\title{
Consumo de mistura mineral e desempenho de bezerros alimentados com sucedâneos do leite
}

\author{
[Intake of mineral supplement and performance of calves fed milk replaces] \\ T.C. Costa ${ }^{1}$, S.G. Coelho ${ }^{2 *}$, F.A.P.V. Fontes ${ }^{1}$, A.U. Carvalho ${ }^{2}$, A.M.Q. Lana ${ }^{2}$, M.I.C. Ferreira ${ }^{3}$ \\ C.B. Gonçalves ${ }^{3}$, R.B. Reis ${ }^{2}$, H.M. Saturnino ${ }^{2}$ \\ ${ }^{1}$ Médica veterinária autônoma \\ ${ }^{2}$ Escola de Veterinária - UFMG \\ Caixa postal 567 \\ 30123-970 - Belo Horizonte, MG \\ ${ }^{3}$ Aluna de pós-graduação - EV-UFMG - Belo Horizonte, MG
}

\begin{abstract}
RESUMO
Utilizaram-se 42 bezerros da raça Holandesa para avaliação do consumo de mistura mineral (MM), até os 60 dias. Os animais foram distribuídos em três grupos conforme o sucedâneo fornecido: grupo soro/leite $+\mathrm{MM}$ (SLMM); grupo soro + MM (SMM); e grupo soja/leite + MM (SOMM). Os animais receberam concentrado, feno, MM e água à vontade. A avaliação do ganho de peso foi feita semanalmente. A concentração de glicose plasmática foi medida aos 7, 14 e 21 dias de vida, antes do fornecimento da dieta, e às 3,6 e 9 horas após a primeira refeição. Realizaram-se hemogramas semanais para avaliações clínicas. Aos 30 e aos 60 dias, colheram-se sangue e urina de cinco animais de cada grupo, os quais foram sacrificados para obtenção de fragmentos do fígado, para análises de minerais. Os animais do grupo SMM apresentaram menores consumos de concentrado e matéria seca total (MST) entre a sexta e oitava semanas $(\mathrm{P}<0,05)$, com consumo de concentrado de 674,72; 1.080,02 e 1.223,65g/a/d e consumo de MST de 699,33; 1.134,31 e 1.287,84g/a/d, para os animais dos grupos SMM, SLMM e SOMM, respectivamente. No consumo de feno, houve interação grupos versus semanas $(\mathrm{P}<0,05)$. O ganho de peso foi maior nos animais do grupo SOMM, 2,18kg/a/d que nos do grupo SMM, 1,13kg/a/d $(\mathrm{P}<0,05)$. O consumo médio da MM no primeiro mês foi de $9,00 \mathrm{~g} / \mathrm{a} / \mathrm{d}$ e da quinta a oitava semanas foi $4,62 \mathrm{~g} / \mathrm{a} / \mathrm{d}$. A concentração de glicose plasmática foi diferente entre as idades e os tempos $(\mathrm{P}<0,05)$.
\end{abstract}

Palavras-chave: bezerro, cobre, glicose, hemograma, minerais

\begin{abstract}
Forty-two Holstein calves were used to evaluate the mineral supplement (MS) intake up to 60-day-old. The calves were divided into three groups, according to the milk replacer: whey/milk + MS (WMMS); whey + MS (WMS) and soy/milk + MS (SMMS). Commercial calf starter, hay, MS and water were offered "ad libitum", and the intake was measured daily. Body weight was monitored once a week and blood glucose levels were quantified on 14, 21 and 28-day-old and also before the supply of the diets, 3, 6 and 9 hours after feeding. Blood samples were collected weekly for blood count. On 30 and 60-day-old, five calves of each group had blood and urine samples collected for serum copper determination. After then, the animals were slaughtered and liver fragments were analyzed for minerals contents. It was found that between the sixth and eighth weeks, the calves from WMS group decreased the intake $(P<0.05)$ of starter 674.72g/day and total dry matter $($ TDM) 699.33 when compared to the calves from WMMS and SMMS groups, which consumed an average of 1,080.02 and 1,223.65g/day of concentrate and 1,134.31 and 1,287.84g/day of TDM respectively. Animals from SMMS group presented higher weight gain $(2.18 \mathrm{~kg} /$ week) than MMS ones $(1.13 \mathrm{~kg} /$ week; $P<0.05)$. The intake mean of $M M$ in the first month was $9.00 \mathrm{~g} / \mathrm{a} / \mathrm{d}$ and after the first month was $4.62 \mathrm{~g} / \mathrm{a} / \mathrm{d}$. Blood glucose levels were different among ages and times after feeding $(P<0.05)$.
\end{abstract}

Keywords: calf, blood count, copper, glucose, mineral

Recebido em 25 de agosto de 2005

Aceito em 7 de maio de 2007

*Autor para correspondência (corresponding author)

E-mail: sandra@vet.ufmg.br

Apoio: FAPEMIG (CAG 477/01-03) 


\section{INTRODUÇÃO}

A concentração dos minerais essenciais deve ser mantida dentro dos limites nutricionais estabelecidos para que haja integridade funcional e estrutural dos tecidos, assegurando, dessa forma, o crescimento, a saúde e a produtividade animal. A ingestão contínua de dietas deficientes, desbalanceadas ou com quantidades excessivas de minerais induz a mudanças na forma $\mathrm{e}$ concentração dos minerais nos tecidos e fluidos corporais, acima ou abaixo dos limites toleráveis. Como forma de prevenção da ocorrência de lesões bioquímicas e alterações nas funções fisiológicas normais, os animais devem ser supridos com dietas palatáveis e sem risco de intoxicação, ou seja, que contenham a quantidade de minerais que atendam suas exigências, assim como os demais nutrientes. As deficiências ou os excessos minerais assumem grande importância na nutrição animal, devido à extensão e facilidade com a qual podem ser confundidas com os efeitos relacionados à subnutrição, aos déficits protéicos e até mesmo aos sintomas de infestações parasitárias, segundo Underwood e Suttle (1999).

Durante a fase de aleitamento, as principais fontes de minerais encontram-se no colostro e no leite ou sucedâneos do leite (Davis e Drackley, 1998; Underwood e Suttle, 1999). O leite apresenta concentrações marginais ou deficientes em todos os microminerais, com exceção do zinco. Dessa forma, os animais que recebem leite como única fonte nutricional durante extenso período podem desenvolver sintomas relacionados à deficiência mineral e ao retardo do crescimento, pois os estoques minerais nos tecidos dos animais são suficientes para assegurar, por apenas algumas semanas de vida, o seu desenvolvimento normal (Davis e Drackley, 1998). Os sucedâneos formulados com base nas exigências nutricionais dos animais são uma alternativa para substituir o fornecimento de leite, bem como evitar os efeitos do desbalanço de nutrientes inorgânicos nessa fase inicial da vida dos bezerros.

Poucos dados referentes ao consumo de mistura mineral por bezerros durante a fase de aleitamento são encontrados na literatura. Os objetivos deste trabalho foram comparar consumo de mistura mineral, desempenho, perfil corporal de minerais, hemograma, glicose plasmática em bezerros alimentados com diferentes sucedâneos do leite.

\section{MATERIAL E MÉTODOS}

Foram utilizados 42 bezerros machos da raça Holandesa, alojados em gaiolas individuais e provenientes de fazendas localizadas em vários municípios. Imediatamente após o nascimento nas fazendas de origem, os animais receberam quatro litros de colostro, provenientes de um banco de colostro preparado para o período experimental. Transportados para o local do experimento, os bezerros foram prontamente examinados e mantidos por três dias para adaptação, quando receberam, duas vezes ao dia, quatro litros de leite em pó reconstituído. Nesse período, foram pesados diariamente. A partir do terceiro dia, com base nos pesos iniciais, os animais foram distribuídos de forma aleatória nos grupos experimentais, com objetivo de manter amostras equivalentes de pesos; os pesos foram mensurados a cada sete dias, antes do fornecimento dos alimentos.

De cada grupo experimental, formado por 14 animais, sacrificaram-se cinco animais aos 30 dias e cinco aos 60 dias de vida. Diariamente, realizaram-se avaliações quanto às suas condições físicas. Nos animais que apresentaram alguma alteração dos sinais clínicos, realizaramse exames mais detalhados e intervenção medicamentosa quando necessária.

Os animais foram distribuídos em grupos conforme a dieta líquida. Os do grupo soro/leite + mistura mineral (SLMM) receberam quatro litros de sucedâneo SL (soro/leite) - 41,6\% da PB vinda do concentrado protéico do soro (CPS), $23,1 \%$ do soro do leite e $35,3 \%$ do leite em pó integral + mistura mineral; os do grupo soro + mistura mineral (SMM) receberam quatro litros de sucedâneo $\mathrm{S}$ (soro) $-68 \%$ da $\mathrm{PB}$ vinda do CPS e $32 \%$ do soro de leite + mistura mineral; e os do grupo soja/leite +mistura mineral (SOMM) receberam quatro litros de sucedâneo SO (soja/leite) $-5,6 \%$ da PB vinda do CPS, $25,8 \%$ do soro de leite, $17,2 \%$ do leite em pó integral e $51,4 \%$ da soja micronizada + mistura mineral. As formulações dos sucedâneos experimentais encontram-se na Tab. 1. As dietas líquidas foram fornecidas até 30 de idade. 
Tabela 1. Ingredientes e níveis de inclusão expressos em porcentagem da matéria seca, de acordo com os sucedâneos fornecidos a bezerros

\begin{tabular}{lccc}
\hline Ingrediente & Sucedâneo SL & Sucedâneo S & Sucedâneo SO \\
\hline CPS & 10,70 & 17,50 & 1,50 \\
Soro em pó & 35,50 & 49,00 & 41,10 \\
Leite em pó & 28,00 & - & 14,10 \\
Soja micronizada & - & - & 24,90 \\
Glicose de milho & 9,40 & 10,50 & - \\
Banha & 10,00 & 18,50 & 15,70 \\
Premix & 1,00 & 1,00 & 1,00 \\
Lecitina de soja & 1,00 & 1,00 & 1,00 \\
Inerte & 3,30 & - & - \\
Fosfato bicálcico & 1,10 & 2,00 & - \\
Calcário calcítico & - & 0,60 & 0,70 \\
\hline
\end{tabular}

$\mathrm{CPS}=$ concentrado protéico do soro, $\mathrm{SL}=$ soro/leite, $\mathrm{S}=$ soro, $\mathrm{SO}=$ soja/leite.

Nas Tab. 2 e 3 são apresentadas, respectivamente, a composição nutricional e mineral dos sucedâneos.

Até o terceiro dia de vida, a dieta líquida de todos os grupos foi à base de colostro no primeiro dia e leite em pó integral reconstituído nos outros dois dias. $\mathrm{O}$ fornecimento de sucedâneo, feito em baldes, foi dividido em duas refeições (dois litros em cada refeição), às 7 e 16 horas até 30 dias de vida. Os sucedâneos utilizados foram especialmente produzidos para este experimento e sua diluição respeitou o teor de matéria seca (MS) de cada formulação, com o objetivo de atingir $13 \%$ de MS do produto diluído, pronto para ser oferecido aos bezerros na temperatura de $37^{\circ} \mathrm{C}$.
Os animais receberam a mesma dieta sólida, composta por concentrado, feno e mistura mineral à vontade a partir dos terceiro dia de idade (Tab. 2, 3 e 4).

Dos 31 aos 60 dias, os animais continuaram recebendo água, concentrado, feno e mistura mineral. O consumo de concentrado e de feno foi mensurado diariamente, e o de mistura mineral a cada dois dias. Utilizaram-se concentrado comercial peletizado, destinado especificamente a bezerros, e feno de Tifton 85, picado em partículas de cinco centímetros. Na mensuração do consumo de água, foi descontada a evaporação, por meio de um balde indicador, fixado próximo às gaiolas, com quantidade similar à oferecida aos animais. Os valores das análises de sódio e potássio na água fornecida foram de 0,09 e $0,01 \mathrm{ppm}$, respectivamente.

Tabela 2. Teores médios de matéria seca (MS), proteína bruta (PB), extrato etéreo (EE), fibra bruta (FB), fibra em detergente neutro (FDN), fibra em detergente ácido (FDA), cálcio (Ca) e fósforo (P), de acordo com os sucedâneos e com o concentrado e feno, expressos em porcentagem da matéria seca, fornecidos a bezerros

\begin{tabular}{lccccc}
\hline & Sucedâneo SL & Sucedâneo S & Sucedâneo SO & Concentrado & Feno \\
\hline MS & 93,6 & 94,0 & 93,5 & 89,2 & 90,3 \\
PB & 25,8 & 26,0 & 26,2 & 21,7 & 11,3 \\
EE & 19,3 & 19,0 & 18,9 & 3,1 & 1,8 \\
FB & 1,3 & 1,4 & 1,6 & - & - \\
FDN & - & - & - & - & 83,9 \\
FDA & - & - & - & - & 40,8 \\
$\mathrm{Ca}^{1}$ & 1,08 & 1,03 & 1,09 & 1,9 & 0,48 \\
$\mathrm{P}^{1}$ & 0,67 & 0,65 & 0,67 & 0,96 & 0,32 \\
\hline
\end{tabular}

${ }^{1}$ Segundo Nutrient...(2001). $\mathrm{SL}=$ soro/leite, $\mathrm{S}=$ soro, $\mathrm{SO}=$ soja/leite. 
Tabela 3. Concentração de cobre, zinco, ferro, manganês, magnésio, potássio e sódio do concentrado, feno e sucedâneos, expressos em $\mathrm{mg} / \mathrm{kg}$ da matéria seca, fornecidos a bezerros

\begin{tabular}{lccccc} 
& Concentrado & Feno & Sucedâneo SL & Sucedâneo S & Sucedâneo SO \\
\hline Cobre & 27,66 & 5,15 & 5,00 & 33,00 & 33,00 \\
Zinco & 150,84 & 86,63 & 60,00 & 240,00 & 50,00 \\
Ferro & 817,46 & 209,15 & 500,00 & 300,00 & 100,00 \\
Manganês & 73,33 & 97,42 & 50,00 & 70,00 & 40,00 \\
Magnésio & $3.437,54$ & $3.750,54$ & 0,00 & 0,00 & 0,00 \\
Potássio & $8.099,44$ & $7.009,19$ & - & - & - \\
Sódio & $2.717,61$ & 755,73 & - & - & - \\
\hline
\end{tabular}

$\mathrm{SL}=$ soro/leite, $\mathrm{S}=$ soro, $\mathrm{SO}=$ soja/leite.

Tabela 4. Concentrações médias de cálcio, fósforo, sódio, potássio, magnésio, zinco, ferro, cobre, cobalto e manganês referentes à mistura mineral fornecida a bezerros, expressas em porcentagem ou $\mathrm{mg} / \mathrm{kg}$ na matéria seca nos macrominerais ou nos microminerais, respectivamente

\begin{tabular}{lc}
\hline Mineral & Concentração \\
\hline Cálcio & 11,65 \\
Fósforo & 7,31 \\
Sódio & 31,68 \\
Potássio & 9,75 \\
Magnésio & 0,30 \\
Zinco & 292,50 \\
Ferro & 97,50 \\
Cobre & 97,50 \\
Cobalto & $3.318,36$ \\
Manganês & 195,00 \\
\hline
\end{tabular}

Os hemogramas foram realizados entre a segunda e a oitava semanas de vida, e a análise de glicose aos 14, 21 e 28 dias, nos tempos zero (antes da primeira alimentação do dia) e às $3,6 \mathrm{e}$ 9 horas após a alimentação. As amostras de sangue foram coletadas da veia jugular, em tubos vacuntainer com EDTA para a realização dos hemogramas e vacuntainer com EDTA adicionado de fluoreto de potássio para as análises de glicose.

Aos 30 e 60 dias de vida, cinco bezerros de cada grupo foram pesados e sacrificados, por eletrocussão precedida de anestesia, para avaliações do cobre e zinco no fígado e cobre no soro sangüíneo e na urina. As amostras de sangue foram coletadas imediatamente antes do sacrifício dos animais, e a urina após o abate. As amostras do fígado $(100 \mathrm{~g})$, coletadas no lobo direito (porção dorsal), foram congeladas à temperatura aproximada de $-20^{\circ} \mathrm{C}$.

Amostras dos alimentos e sobras foram colhidas quinzenalmente para determinação dos teores de matéria seca (MS) a $105^{\circ} \mathrm{C}$, proteína bruta (PB), conforme o método de Kjeldhal, cálcio (Ca) e fósforo (P), segundo a AOAC (Official..., 1980). Para determinação dos componentes da parede celular, usou-se método seqüencial de Van Soest et al. (1991).

O preparo das amostras dos alimentos, fígado, urina e soro sangüíneo, para análises de minerais, foi feito por via seca, segundo Silva e Queiroz (2002). Os teores de $\mathrm{Zn}, \mathrm{Cu}, \mathrm{Fe}$, Co e Mn foram determinados no aparelho de espectrofotômetro de absorção atômica ${ }^{1}$, e os de $\mathrm{Na}, \mathrm{K}$ e $\mathrm{Mg}$ no aparelho fotômetro de chama ${ }^{2}$.

Os hemogramas foram realizados no aparelho automático ${ }^{3}$. Os dados gerados foram contagem de leucócitos, hemoglobina, hematócrito e hemácias.

Para dosagem dos níveis de glicose plasmáticos, utilizou-se o método colorimétrico por meio do

${ }^{1}$ Perkinelmer do Brasil Ltda (modelo 3110) - Perdizes, SP - Brasil.

${ }^{2}$ Celm - Cia Equipadora de Laboratórios Modernos (modelo FC-280) - Barueri, SP - Brasil.

${ }^{3}$ Horiba ABX Diagnostics Ltda (ABX VET ABC) - São Paulo, SP - Brasil. 
$k_{i t}{ }^{4}$. Para os dados de consumo de alimentos (concentrado, feno, mistura mineral e água), ganho de peso e hemogramas, empregou-se o delineamento inteiramente ao acaso, em esquema de parcelas subdivididas, com grupos nas parcelas e tempos nas subparcelas.

Para as concentrações de cobre e zinco no fígado e de cobre no soro e na urina, utilizou-se delineamento inteiramente ao acaso, com cinco repetições, em arranjo fatorial $5 \times 2$ (5 grupos e 2 idades). Para os dados de concentração plasmática de glicose, empregou-se o delineamento experimental inteiramente ao acaso em esquema de parcelas sub-subdivididas, com as parcelas representadas pelos grupos, as subparcelas pelas idades e as subsubparcelas pelos tempos. As diferenças entre as médias foram testadas por meio do teste Duncan a $5 \%$ de probabilidade. Utilizaram-se os procedimentos estatísticos SAEG (Sistema..., 1998). A homocedasticidade e a normalidade dos dados foram avaliadas. Quando pelo menos uma das condições não foi atendida, os dados foram transformados. Nos dados de consumo de concentrado e água, utilizou-se a função raiz +1 . A função $\log +1$ foi aplicada na análise do consumo de feno e de mistura mineral, e no consumo de matéria seca total foi utilizada a função raiz. A análise da concentração de cobre na urina foi não paramétrica, com utilização do teste Kruskal-Walliis $(\mathrm{P}=0,05)$. Os demais dados não foram transformados, e para os hemogramas, fizeram-se apenas análises descritivas.

\section{RESULTADOS E DISCUSSÃO}

Os dados do consumo médio diário de concentrado encontram-se na Tab. 5. O consumo foi diferente entre os grupos e entre as semanas experimentais $(\mathrm{P}<0,05)$. Durante a segunda, terceira, quarta, quinta e oitava semanas, houve acréscimo $(\mathrm{P}<0,05)$ no consumo, mas, na fase de aleitamento entre a primeira e quarta semanas, $\mathrm{o}$ consumo foi baixo.

Com o desaleitamento, o consumo aumentou substancialmente, atribuído à busca do animal em atingir as exigências nutricionais, frente à ausência da dieta líquida. Os bezerros do grupo

${ }^{4}$ Bioclin - Quibasa - Química Básica Ltda - Belo Horizonte, MG - Brasil.
SMM consumiram menos concentrado que os dos demais grupos $(\mathrm{P}<0,05)$ entre a sexta e a oitava semanas.

O consumo médio diário de feno (Tab. 5) mostra que houve diferença entre os grupos, nas semanas e também efeito de interação semana versus grupo $(\mathrm{P}<0,05)$. Os animais dos grupos SLMM e SOMM aumentaram $(\mathrm{P}<0,05)$ o consumo de feno na terceira, quarta e quinta semanas; a partir desta, os do grupo SOMM estabilizaram o consumo, o que só ocorreu com os do grupo SLMM na oitava semana. No grupo SMM, houve aumento $(\mathrm{P}<0,05)$ na quarta e sexta semanas, quando então o consumo se estabilizou.

Semelhante ao ocorrido com o concentrado, o consumo de feno durante a fase de aleitamento foi baixo, mas aumentou após a retirada da dieta líquida e a conseqüente elevação de ingestão de alimentos sólidos. Os animais do SMM consumiram menos feno que os dos demais grupos entre a terceira e sexta semana $(\mathrm{P}<0,05)$.

$\mathrm{Na}$ Tab. 5 apresentam-se os dados do consumo médio diário de matéria seca total (MST). Houve diferenças entre grupos e semanas e observou-se interação de grupo versus semana $(\mathrm{P}<0,05)$. Observou-se aumento entre a segunda e a quinta semanas e também na oitava $(\mathrm{P}<0,05)$. Durante a fase de aleitamento, o consumo de MST foi baixo, e ocorreu elevação principalmente a partir da retirada da dieta líquida, com um mês de idade. Dessa forma, da quinta semana em diante, os valores do consumo médio diário de MST aumentaram de forma mais expressiva.

Ocorreu menor consumo de MST no grupo SMM $(\mathrm{P}<0,05)$ em relação aos demais grupos, entre a sexta e oitava semanas, pois esses animais consumiram menos concentrado $(\mathrm{P}<0,05)$ nesse período.

O consumo médio de mistura mineral (MM) foi semelhante entre os grupos avaliados $(\mathrm{P}>0,05)$, entretanto observou-se diferença entre as semanas $(\mathrm{P}<0,05)$ (Tab. 5). Os animais, durante a primeira semana, consumiram mais MM que nas semanas seguintes. Inicialmente supôs-se que esse consumo fosse atribuído à curiosidade dos animais, entretanto houve procura pela $\mathrm{MM}$ durante todo período avaliado, sugerindo, dessa forma, ter sido induzido pelas necessidades nutricionais e não apenas por curiosidades. 
Tabela 5. Consumo médio diário na matéria seca de concentrado, feno, matéria seca total (MST), mistura mineral (MM), e água por bezerros, e ganho de peso, segundo os grupos e semanas do experimento

\begin{tabular}{|c|c|c|c|c|c|c|c|c|c|c|}
\hline \multirow[b]{2}{*}{ Grupo } & \multicolumn{10}{|c|}{ Semana } \\
\hline & 1 & 2 & 3 & 4 & 5 & 6 & 7 & 8 & Média & $\begin{array}{l}\text { CV } \\
(\%)\end{array}$ \\
\hline \multicolumn{11}{|c|}{ Consumo de concentrado (g/a/d) } \\
\hline SLMM & $37,36 \mathrm{fA}$ & $152,21 \mathrm{eA}$ & $354,72 \mathrm{dA}$ & $634,08 \mathrm{cA}$ & $842,20 \mathrm{bcA}$ & $986,38 \mathrm{abA}$ & $966,24 \mathrm{abA}$ & $1287,46 \mathrm{aA}$ & 657,58 & \\
\hline SMM & $32,75 \mathrm{cA}$ & $133,23 \mathrm{bA}$ & $215,05 \mathrm{bA}$ & $441,00 \mathrm{aA}$ & $610,97 \mathrm{aA}$ & $609,80 \mathrm{aB}$ & $634,84 \mathrm{aB}$ & $779,54 \mathrm{aB}$ & 432,15 & \\
\hline SOMM & $75,71 \mathrm{fA}$ & $71,65 \mathrm{eA}$ & $187,08 \mathrm{eA}$ & $397,52 \mathrm{dA}$ & $819,51 \mathrm{cA}$ & $943,27 b c A$ & $1226,29 \mathrm{abA}$ & $1501,41 \mathrm{aA}$ & 652,80 & \\
\hline Média & 48,60 & 119,03 & 252,83 & 490,87 & 757,56 & 846,48 & 942,46 & 1189,47 & & 17,8 \\
\hline \multicolumn{11}{|c|}{ Consumo de feno $(\mathrm{g} / \mathrm{a} / \mathrm{d})$} \\
\hline SLMM & $10,84 \mathrm{cA}$ & $1,27 \mathrm{eA}$ & $4,17 \mathrm{dA}$ & $19,25 \mathrm{cA}$ & $30,58 \mathrm{bA}$ & $50,78 \mathrm{abA}$ & 47,20abA & $64,90 \mathrm{aA}$ & 28,62 & \\
\hline SMM & $5,52 \mathrm{bA}$ & $0,24 \mathrm{cA}$ & $1,13 \mathrm{cB}$ & $5,23 \mathrm{bB}$ & $6,54 \mathrm{bB}$ & $20,79 \mathrm{aB}$ & $27,34 \mathrm{aA}$ & $25,70 \mathrm{aA}$ & 11,56 & \\
\hline SOMM & $1,34 \mathrm{~dB}$ & $1,21 \mathrm{dA}$ & $8,70 \mathrm{cA}$ & $21,84 \mathrm{bA}$ & $45,13 \mathrm{aA}$ & $55,07 \mathrm{aA}$ & $65,17 \mathrm{aA}$ & $72,34 \mathrm{aA}$ & 33,85 & \\
\hline Média & 5,90 & 0,90 & 4,67 & 15,44 & 27,42 & 42,21 & 46,57 & 54,31 & & 25,9 \\
\hline \multicolumn{11}{|c|}{ Consumo de MST (g/a/d) } \\
\hline SLMM & $48,20 \mathrm{fA}$ & $153,48 \mathrm{cA}$ & $358,89 \mathrm{dA}$ & $653,32 \mathrm{cA}$ & $872,77 \mathrm{bcA}$ & $1.037,16 \mathrm{abA}$ & $1.013,43 \mathrm{abA}$ & $1.352,36 \mathrm{aA}$ & 686,20 & \\
\hline SMM & $38,26 \mathrm{dA}$ & $133,47 \mathrm{cdA}$ & $216,17 \mathrm{cA}$ & $446,22 \mathrm{bA}$ & $617,50 \mathrm{abA}$ & $630,58 \mathrm{abB}$ & $662,17 \mathrm{abB}$ & $805,24 \mathrm{aB}$ & 443,70 & \\
\hline SOMM & $77,05 \mathrm{fA}$ & $72,85 \mathrm{fA}$ & $195,78 \mathrm{eA}$ & $419,35 \mathrm{dA}$ & $864,64 \mathrm{cA}$ & $998,34 \mathrm{bcA}$ & $1291,46 \mathrm{abA}$ & $1573,74 \mathrm{aA}$ & 686,65 & \\
\hline Média & 54,50 & 119,93 & 256,94 & 506,29 & 784,97 & 888,69 & 989,02 & 1243,78 & & 17,3 \\
\hline \multicolumn{11}{|c|}{ Consumo de MM (g/a/d) } \\
\hline SLMM & 7,87 & 4,40 & 4,97 & 2,21 & 3,81 & 2,75 & 3,34 & 1,69 & $3,88 \mathrm{~A}$ & \\
\hline SMM & 9,78 & 7,37 & 5,50 & 3,24 & 3,91 & 4,47 & 2,11 & 3,90 & $5,0 \mathrm{~A}$ & \\
\hline SOMM & 14,75 & 14,05 & 12,16 & 10,73 & 11,60 & 7,92 & 7,78 & 4,27 & $10,41 \mathrm{~A}$ & \\
\hline Média & $12,38 \mathrm{a}$ & $9,28 \mathrm{ab}$ & $8,4 a b$ & $5,96 \mathrm{bc}$ & $6,77 \mathrm{abc}$ & $4,86 \mathrm{bc}$ & $3,94 \mathrm{c}$ & $2,92 \mathrm{c}$ & & 12,4 \\
\hline \multicolumn{11}{|c|}{ Consumo de água $(1 / \mathrm{a} / \mathrm{d})$} \\
\hline SLMM & 0,55 & 0,69 & 0,51 & 0,77 & 1,91 & 3,57 & 3,22 & 3,56 & $1,85 \mathrm{~A}$ & \\
\hline SMM & 0,24 & 0,48 & 0,32 & 0,33 & 1,58 & 3,37 & 2,89 & 2,86 & $1,51 \mathrm{~A}$ & \\
\hline SOMM & 0,59 & 0,59 & 0,71 & 0,69 & 2,11 & 4,12 & 3,81 & 5,26 & $2,24 \mathrm{~A}$ & \\
\hline Média & $0,46 \mathrm{c}$ & $0,59 \mathrm{c}$ & $0,51 \mathrm{c}$ & $0,60 \mathrm{c}$ & $1,87 \mathrm{~b}$ & $3,69 \mathrm{a}$ & $3,31 \mathrm{a}$ & $3,89 \mathrm{a}$ & & 30,6 \\
\hline \multicolumn{11}{|c|}{ Ganho de peso $(\mathrm{kg} / \mathrm{a} / \mathrm{s})$} \\
\hline SLMM & 0,64 & 1,12 & 2,12 & 2,48 & 1,36 & 2,12 & 1,48 & 3,44 & $1,84 \mathrm{AB}$ & \\
\hline SMM & 0,09 & $-0,52$ & 0,64 & 2,12 & 0,44 & 3,36 & 1,84 & 1,06 & $1,13 \mathrm{~B}$ & \\
\hline SOMM & 0,93 & 0,16 & 0,16 & 2,72 & 1,76 & 2,00 & 4,68 & 5,04 & $2,18 \mathrm{~A}$ & \\
\hline Média & $0,55 \mathrm{c}$ & $0,25 \mathrm{c}$ & $0,97 \mathrm{c}$ & $2,44 \mathrm{ab}$ & $1,19 \mathrm{bc}$ & $2,49 \mathrm{ab}$ & $2,67 \mathrm{ab}$ & $3,18 \mathrm{a}$ & & 109,1 \\
\hline
\end{tabular}
soro/leite + MM, SMM= sucedâneo soro + MM, SOMM= sucedâneo soja/leite $+\mathrm{MM}, \mathrm{g} / \mathrm{a} / \mathrm{d}=\mathrm{grama} / \mathrm{animal} / \mathrm{dia} ; \mathrm{l} / \mathrm{a} / \mathrm{d}=\mathrm{litro} / \mathrm{animal} / \mathrm{dia} ; \mathrm{kg} / \mathrm{a} / \mathrm{s}=\mathrm{quilograma} / \mathrm{animal} / \mathrm{semana}$.

Os animais consumiram mais MM durante a fase de aleitamento, apresentando valores médios diários durante o primeiro mês de $9,00 \mathrm{~g} / \mathrm{a} / \mathrm{d}$, atribuído à baixa ingestão de alimentos sólidos nesse período e, conseqüentemente, maior necessidade de ingerir MM, visando atender às suas necessidades nutricionais. Com a retirada da dieta líquida, o consumo de MM foi reduzido e, assim, o valor médio diário entre a quinta e a oitava semanas foi de apenas $4,62 \mathrm{~g} / \mathrm{a} / \mathrm{d}$.

O consumo médio diário de água é apresentado na Tab. 5. Ele foi semelhante entre os grupos $(\mathrm{P}>0,05)$, entretanto observou-se aumento gradativo com o avançar das semanas avaliadas, com consumo médio diário de $0,54 \mathrm{l} / \mathrm{a} / \mathrm{d}$ durante a fase de aleitamento. Somente a partir do desaleitamento o consumo foi diferente $(\mathrm{P}<0,05)$, com consumo médio de 3,19 1/a/d. Segundo Davis e Drackley (1998), durante a fase de aleitamento, o consumo de água é baixo, pois os animais ingerem água através da dieta líquida, o que reduz sua necessidade, em situações de termoneutralidade, como nas condições em que foi realizado este experimento. Esse aumento do consumo de água a partir do desaleitamento deve-se à elevação na ingestão de MST.

Os valores médios de ganho de peso médio semanal foram diferentes entre os grupos e entre as semanas avaliadas $(\mathrm{P}<0,05)$ (Tab. 5). Durante a fase de aleitamento, os ganhos foram baixos, 
principalmente entre as três primeiras semanas. Dessa forma, com o desaleitamento e o aumento da ingestão dos alimentos sólidos, os animais apresentaram maiores ganhos de peso, como pôde ser observado entre a quarta e a oitava semanas. Vale ressaltar que, durante a quinta semana, houve redução do ganho de peso. Nessa fase, o consumo médio de MST ainda apresentou baixos valores em todos os grupos $(784,97 \mathrm{~g} / \mathrm{a} / \mathrm{dia})$. Essa observação indica que os animais ainda não conseguiam ingerir quantidades suficientes de matéria seca proveniente do concentrado e feno, em substituição à matéria seca vinda da dieta líquida. Esse fato, aliado ao estresse do desaleitamento, provocou a queda no ganho de peso.

$\mathrm{Na}$ desmama precoce, quase inevitavelmente ocorre perda de peso, pois, na retirada da dieta líquida, os animais ainda não conseguem ingerir quantidades suficientes de MST que atendam suas exigências nutricionais. Os animais do grupo SMM ganharam menos peso $(\mathrm{P}<0,05)$ em relação ao grupo SOMM. Fontes et al. (2006) observaram que os animais que receberam sucedâneo formulado unicamente com a proteína do soro do leite como fonte de proteína ganharam menos peso. Tal fato pode estar relacionado com a ausência de caseína na formulação desse sucedâneo, conseqüentemente sem formação de coágulos no abomaso, o que propicia a rápida chegada de grande quantidade de nutrientes no intestino delgado logo após a alimentação, sobrecarregando o sistema digestivo e, como conseqüência, provocando menor digestão e absorção dos nutrientes.

A concentração de glicose plasmática é apresentada na Tab. 6. Observaram-se diferenças entre as idades e os tempos avaliados $(\mathrm{P}<0,05)$. Essas diferenças na concentração de glicose plasmática nos tempos já eram esperadas, devido ao fato de os animais ainda serem préruminantes, sendo o sucedâneo a principal fonte de energia para eles durante o primeiro mês de vida.

Tabela 6. Concentração de glicose plasmática $(\mathrm{mg} / \mathrm{dl})$ segundo os grupos, as idades dos bezerros e os tempos após o fornecimento da dieta

\begin{tabular}{|c|c|c|c|c|c|c|}
\hline \multirow{2}{*}{ Grupo } & \multirow{2}{*}{ Idade (dias) } & \multicolumn{5}{|c|}{ Tempo (horas) } \\
\hline & & 0 & 3 & 6 & 9 & Média \\
\hline SLMM & 14 & 90,85 & 112,12 & 108,33 & 95,61 & 101,73 \\
\hline SMM & 14 & 75,96 & 100,19 & 99,72 & 92,69 & 92,14 \\
\hline SOMM & 14 & 84,51 & 108,08 & 101,64 & 89,46 & 95,92 \\
\hline Média & 14 & - & - & - & - & $96,60 \mathrm{~A}$ \\
\hline SLMM & 21 & 72,31 & 91,23 & 85,38 & 77,83 & 81,69 \\
\hline SMM & 21 & 75,80 & 103,23 & 91,81 & 83,69 & 88,63 \\
\hline SOMM & 21 & 72,90 & 97,90 & 91,05 & 86,56 & 87,10 \\
\hline Média & 21 & - & - & - & - & $85,81 \mathrm{~B}$ \\
\hline SLMM & 28 & 75,87 & 86,05 & 86,49 & 82,82 & 82,81 \\
\hline SMM & 28 & 67,22 & 95,18 & 91,70 & 79,59 & 83,42 \\
\hline SOMM & 28 & 75,00 & 105,26 & 81,77 & 69,17 & 82,80 \\
\hline Média & 28 & - & - & - & - & $83,01 \mathrm{~B}$ \\
\hline Média (tempo) & - & $76,71 d$ & $99,92 \mathrm{a}$ & $93,10 \mathrm{~b}$ & $84,15 \mathrm{c}$ & - \\
\hline
\end{tabular}

Médias seguidas por letras distintas, maiúsculas na coluna e minúsculas na linha, diferem entre si pelo teste Duncan $(\mathrm{P}<0,05) . \mathrm{CV}=10,1 \% . \mathrm{MM}=$ mistura mineral, $\mathrm{SLMM}=$ sucedâneo soro/leite $+\mathrm{MM}, \mathrm{SMM}=$ sucedâneo soro $+\mathrm{MM}$, $\mathrm{SOMM}=$ sucedâneo soja/leite $+\mathrm{MM}$.

Dessa forma, os valores nos tempos de 3 e 6 horas após o fornecimento dos sucedâneos foram mais altos que nos tempos zero (jejum) e com 9 horas após o fornecimento da dieta líquida.

Com o avançar da idade, os níveis de glicose estão sujeitos à menor variação entre os tempos e apresentam menores valores quando comparados à idade de 14 dias. Esse fato justifica-se pelo desenvolvimento do rúmen e pela adaptação do metabolismo dos bezerros, que iniciam a utilização dos produtos provenientes da fermentação ruminal dos carboidratos no rúmen. 
Não houve diferenças quanto à concentração de cobre hepático entre os grupos e entre as idades. Segundo Underwood e Suttle (1999), a faixa normal de variação da concentração de cobre no fígado de bezerros está entre 50,5 a $201,6 \mathrm{mg} / \mathrm{kg}$ na MS. Dessa forma, os valores encontrados neste experimento estão bem acima do limite inferior, o que pode estar relacionado ao fato de os sucedâneos terem sido formulados para atender as exigências de minerais. Além disso, a inclusão da mistura mineral junto ao sucedâneo pode ter facilitado a sua absorção.

As concentrações de cobre no soro sangüíneo foram semelhantes entre as idades e os grupos $(\mathrm{P}>0,05)$. Os valores encontrados estão um pouco abaixo dos valores de referência para ruminantes, que variam de 0,19 a $0,57 \mathrm{mg} / 1$, entretanto, nos animais jovens, esses valores podem ser até $50 \%$ menor do que nos animais adultos, segundo Underwood e Suttle (1999).

A concentração de cobre na urina mostra que não ocorreu diferença entre os grupos e entre as idades avaliadas $(\mathrm{P}>0,05)$ (Tab. 7), o que é atribuído ao fato de o principal mecanismo de secreção de cobre ser feito pela secreção biliar e não via urina (McDowell, 1992; Underwood e Suttle, 1999). Esses minerais apresentaram concentrações adequadas nos dois grupos experimentais.

Não houve diferença entre os grupos e entre as idades avaliadas $(\mathrm{P}>0,05)$, quanto à concentração de zinco (Tab. 7).

Tabela 7. Concentração hepática de zinco (na matéria seca - MS), segundo os grupos e as idades dos bezerros

\begin{tabular}{|c|c|c|c|c|}
\hline \multirow[b]{2}{*}{ Grupos } & \multicolumn{3}{|c|}{ Idade } & \multirow[b]{2}{*}{$\mathrm{CV}(\%)$} \\
\hline & 30 & 60 & Média & \\
\hline \multicolumn{5}{|c|}{ Concentração de Cu hepático (mg/kg na MS) } \\
\hline SLMM & 73,56 & 92,30 & 82,93 & \\
\hline SMM & 112,97 & 75,85 & 94,41 & \\
\hline SOMM & 78,20 & 75,68 & 76,94 & \\
\hline Média & $88,24 a$ & $81,28 \mathrm{a}$ & & 35,2 \\
\hline \multicolumn{5}{|c|}{ Concentração de $\mathrm{Cu}$ no soro $(\mathrm{mg} / \mathrm{l})$} \\
\hline SLMM & 0,2514 & 0,1566 & 0,2040 & \\
\hline SMM & 0,1435 & 0,1450 & 0,1442 & \\
\hline SOMM & 0,1616 & 0,1765 & 0,1690 & \\
\hline Média & $0,1855 \mathrm{a}$ & $0,1593 a$ & & 55,9 \\
\hline \multicolumn{5}{|c|}{ Concentração de $\mathrm{Cu}$ na urina $(\mathrm{mg} / \mathrm{l})$} \\
\hline SLMM & 0,046 & 0,052 & 0,049 & \\
\hline SMM & 0,038 & 0,566 & 0,302 & \\
\hline SOMM & 0,029 & 0,208 & 0,118 & \\
\hline Média & $0,037 \mathrm{a}$ & $0,275 \mathrm{a}$ & & - \\
\hline \multicolumn{5}{|c|}{ Concentração de Zn hepático (mg/kg na MS) } \\
\hline SLMM & 34,58 & 62,71 & 48,64 & \\
\hline SMM & 58,33 & 43,13 & 50,73 & \\
\hline SOMM & 26,00 & 83,36 & 54,68 & \\
\hline Média & $39,64 a$ & $63,07 \mathrm{a}$ & & 62,9 \\
\hline
\end{tabular}

Médias seguidas por letras distintas, na linha, diferem entre si pelo teste Duncan $(\mathrm{P}<0,05)$. Teste Kruskal-Walliis $(\mathrm{P}=0,05)$ para análise de $\mathrm{Cu}$ na urina. $\mathrm{MM}=$ mistura mineral, $\mathrm{SLMM}=$ sucedâneo soro/leite $+\mathrm{MM}$, $\mathrm{SMM}=$ sucedâneo soro $+\mathrm{MM}, \mathrm{SOMM}=$ sucedâneo soja/leite $+\mathrm{MM}$.

Os três grupos apresentaram valores abaixo da faixa de normalidade $112,48 \mathrm{mg} / \mathrm{kg}$ na $\mathrm{MS}$, segundo Underwood e Suttle (1999), entretanto, como descrito acima, valores abaixo destes não significam deficiência, sendo necessárias outras avaliações junto à sintomatologia clínica relacionados à deficiência de zinco (Nutrient...,
2001). Os animais deste experimento não apresentaram sintomas de deficiência de $\mathrm{Zn}$.

Os valores médios do número de hemácias, volume globular, hemoglobina e leucócitos nos animais dos grupos SLMM, SMM e SOMM 
encontram-se na Tab. 8. Não foi observada alteração clínica entre os grupos experimentais.

A concentração de hemácias manteve-se entre a faixa de variação desejada, 5 a $10 \times 10^{6} / \mu 1$, segundo Jain, (1986) e Fagliari (1998). Os valores da concentração média de hemácias variaram entre 6,12 a $8,9 \times 10^{6} / \mu 1$, de forma que as concentrações de hemácias aumentaram até a sexta semana e, a partir da sétima e oitava semanas, diminuíram.

Tabela 8. Valores médios do número de hemácias, hemoglobina, volume globular (VG) e de leucócitos, segundo os grupos e a semana de idade dos bezerros

\begin{tabular}{|c|c|c|c|c|c|c|c|c|}
\hline \multirow{2}{*}{ Grupo } & \multicolumn{7}{|c|}{ Semana } & \multirow{2}{*}{ Média } \\
\hline & 2 & 3 & 4 & 5 & 6 & 7 & 8 & \\
\hline \multicolumn{9}{|c|}{ Hemácias $($ x 10\%/ $/ \mu \mathrm{l})$} \\
\hline SLMM & 8,64 & 8,88 & 8,92 & 10,34 & 8,95 & 6,27 & 5,74 & 8,25 \\
\hline SMM & 7,23 & 7,74 & 8,18 & 9,73 & 9,51 & 8,60 & 6,61 & 8,23 \\
\hline SOMM & 5,65 & 6,07 & 6,21 & 6,64 & 7,43 & 7,16 & 6,02 & 6,45 \\
\hline Média & 7,17 & 7,56 & 7,77 & 8,90 & 8,63 & 7,34 & 6,12 & \\
\hline \multicolumn{9}{|c|}{ Hemoglobina $(\mathrm{g} / \mathrm{dl})$} \\
\hline SLMM & 10,30 & 10,44 & 10,27 & 10,69 & 9,52 & 7,47 & 7,96 & 9,52 \\
\hline SMM & 8,76 & 9,10 & 9,32 & 10,44 & 10,29 & 9,52 & 8,36 & 9,40 \\
\hline SOMM & 7,16 & 8,18 & 8,18 & 7,95 & 8,64 & 8,66 & 8,26 & 8,15 \\
\hline Média & 8,74 & 9,24 & 9,26 & 9,69 & 9,48 & 8,55 & 8,19 & \\
\hline \multicolumn{9}{|c|}{ VG $(\%)$} \\
\hline SLMM & 32,96 & 32,42 & 32,00 & 37,49 & 35,00 & 24,33 & 23,16 & 31,05 \\
\hline SMM & 27,34 & 27,92 & 28,54 & 34,48 & 33,66 & 30,50 & 23,83 & 29,47 \\
\hline SOMM & 22,32 & 25,72 & 24,46 & 27,00 & 31,66 & 28,33 & 24,00 & 26,21 \\
\hline Média & 27,54 & 28,69 & 28,33 & 32,99 & 33,44 & 27,72 & 23,66 & \\
\hline \multicolumn{9}{|c|}{ Leucócitos $\left(\right.$ x $\left.10^{3} / \mu \mathrm{l}\right)$} \\
\hline SLMM & 14,04 & 10,00 & 12,44 & 16,44 & 12,60 & 7,83 & 6,13 & 11,35 \\
\hline SMM & 9,96 & 10,44 & 10,63 & 9,09 & 9,63 & 10,26 & 5,73 & 9,39 \\
\hline SOMM & 13,38 & 8,48 & 9,00 & 6,73 & 7,92 & 8,43 & 6,46 & 8,63 \\
\hline Média & 12,46 & 9,64 & 10,69 & 10,75 & 10,05 & 8,84 & 6,11 & \\
\hline
\end{tabular}

$\mathrm{MM}=$ mistura mineral, SLMM= sucedâneo soro/leite $+\mathrm{MM}, \mathrm{SMM}=$ sucedâneo soro $+\mathrm{MM}, \mathrm{SOMM}=$ sucedâneo soja/leite + MM.

A concentração de hemoglobina apresentou valores dentro da faixa ideal, entre 8 a $15 \mathrm{~g} / \mathrm{dl}$, segundo Jain (1986), durante todas as semanas avaliadas. Nas concentrações médias de hemoglobina, ocorreu aumento até a quinta semana e redução nas demais semanas avaliadas. Os valores foram entre 8,19 a 9,69g/dl.

Segundo Jain (1986), em relação ao volume globular, a faixa ideal varia de 24 a $36 \%$, respectivamente, não sendo observado caso de desidratação nos animais. O VG aumentou até a sexta semana, atingindo valores de $33,4 \%$, e diminuiu com o avançar da idade, sendo o menor valor médio de $\mathrm{VG}$ encontrado no experimento de $23,6 \%$, na oitava semana.

Os valores dos leucócitos totais estão dentro da faixa normal de 4 a $12 \times 10^{3} / \mu 1$, segundo Jain (1986). Os valores de leucócitos médios variaram entre $6,1 \times 10^{3} / \mu \mathrm{l}$ na oitava semana a $12,4 \times 10^{3} / \mu \mathrm{l}$ na segunda semana de vida. Os valores de leucócitos ao nascimento são elevados devido à presença de cortisol; com o avançar da idade, observa-se sua diminuição devido à redução do glicocorticóide na circulação sangüínea.

\section{CONCLUSÃO}

Mesmo com o fornecimento de sucedâneos formulados com base nas necessidades nutricionais, os animais dos três grupos experimentais consumiram suplemento mineral, indicando, para melhor entendimento desse comportamento, novos experimentos nessa área. 


\section{REFERÊNCIAS BIBLIOGRÁFICAS}

DAVIS, C.L.; DRACKLEY, J.K. The development, nutrition and management of the young calf. Iowa: Iowa University, 1998. 329 p.

FAGLIARI，J.J.; SANTANA，A.E.; LUCAS, F.A. et al. Constituintes sangüíneos de bovinos recém-nascidos das raças Nelore (Bos indicus) e Holandesa (Bos taurus) e de bubalinos (Bubalus bubalis) da raça Murrah. Arq. Bras. Med. Vet. Zootec., v.50, p.8-14, 1998.

FONTES, F.A.P.V.; COELHO, S.G.; LANA, A.M.Q. et al. Desempenho de bezerros alimentados com dietas líquidas à base de leite integral ou soro de leite. Arq. Bras. Med. Vet. Zootec., v.58, p.212-219, 2006.

JAIN, N.C. Essentials of veterinary hematology. Philadelphia: Lea \& Febiger, 1993. 471p.

McDOWELL, L.R. Minerals in animal and human nutrition. San Diego: Academic, 1992. $516 \mathrm{p}$.
NUTRIENT requirements of dairy cattle. 7.ed. Washington, DC.: NRC, 2001. 381p.

OFFICIAL methods of analysis. 13.ed. Washington, DC: AOAC, 1980. 1015p.

SISTEMA de análises estatísticas e genéticas SAEG. Versão 7.0 Viçosa: UFV, 1998

SILVA, D.J.; QUEIROZ, A.C. Análise de alimentos: métodos químicos e biológicos. Viçosa, MG: UFV, 2002. 235p.

UNDERWOOD, E.J.; SUTTLE, N.F. The mineral nutrition of livestock. 3.ed. London: CABI, 1999. 598p.

VAN SOEST, P.J.; ROBERTSON, J.B.; LEWIS, B. A. Methods for dietary fiber, neutral detergent fiber, and non starch polysaccharides in relation to animal nutrition. J. Dairy Sci., v.74, p.35833597, 1991. 